\title{
Atividades práticas em hortas escolares no processo de ensino e aprendizagem de Geografia para estudantes com deficiência intelectual
}

Juanice Pereira Santos Silva ${ }^{1}$, Ruth Elias de Paula Laranja ${ }^{2}$

\begin{abstract}
Resumo
O presente artigo corresponde aos resultados parciais de uma pesquisa de dissertação de mestrado cujo objetivo foi investigar as possibilidades e os desafios no processo de ensino e aprendizagem de Geografia com atividades práticas em horta escolar. A pesquisa foi fomentada pela observação das dificuldades dos professores de Geografia em trabalhar junto a alunos com deficiência intelectual (DI), devido à escassez de materiais didáticos adequados e à formação docente insuficiente. Os sujeitos do estudo são estudantes com DI, matriculados nas séries finais de uma escola do ensino fundamental na cidade do Gama-DF. Para o respectivo estudo, utilizamos a pesquisa qualitativa como metodologia. A utilização da horta escolar como recurso pedagógico de ensino possibilitou a promoção de uma aprendizagem mais significativa, que contemplou também outras habilidades humanas interessantes para alunos com DI, ao associar os conteúdos geográficos aplicados durante o desenvolvimento das atividades práticas na horta escolar nas aulas de Geografia. No decorrer da pesquisa foi perceptível o quanto as atividades práticas no espaço físico da horta escolar no ensino de Geografia para alunos com DI foram eficazes, deram sentido para a compreensão e reflexão sobre os saberes geográficos, além de fortalecerem ações de inclusão no espaço escolar.
\end{abstract}

\section{Palavras-chave}

Geografia. Ensino. Aprendizagem. Horta escolar. Deficiência intelectual.

\footnotetext{
${ }^{1}$ Doutoranda em Geografia pela Universidade de Brasília, Brasil; professora da rede estadual de educação do Distrito Federal, Brasil. E-mail: juanice.ahss@yahoo.com.br.

${ }^{2}$ Doutora em Geografia pela Universidade Estadual Paulista Júlio de Mesquita Filho, São Paulo, Brasil, com estágio pós-doutoral na Universidade do Porto, Portugal; professora adjunta I do Departamento de Geografia da Universidade de Brasília, Brasil. E-mail: uabruth@gmail.com.
} 


\title{
Practical activities in school gardens in the process of teaching geography learning for students with intellectual disabilities
}

Juanice Pereira Santos Silva ${ }^{3}$, Ruth Elias de Paula Laranja ${ }^{4}$

\begin{abstract}
This text corresponds to the partial results of a master dissertation research which objective was to investigate the possibilities and challenges in the teaching and learning process of Geography with practical activities in a school garden. The research was fostered by the observation of the difficulties of Geography teachers in working with students with intellectual disabilities (ID), due to the lack of adequate teaching materials and insufficient teacher training. The study subjects are students with ID, enrolled in the final grades of elementary school in Gama-DF, Brazil. For the respective study we used qualitative research as a methodology. The use of the school garden as a pedagogical teaching resource enabled the promotion of a more meaningful learning, which also contemplated other human skills, interesting for students with ID, by associating the geographical contents applied during the development of practical activities in the school garden, in geography classes. Throughout the research it was noticeable how effective the practical activities in the physical space of the school garden in teaching Geography to students with ID were effective, gave meaning to understanding and reflection of geographical knowledge, and strengthened actions of inclusion in the school space.
\end{abstract}

\section{Keywords}

Geography. Teaching. Learning. School Garden. Intellectual disability.

\footnotetext{
${ }^{3} \mathrm{PhD}$ student in Geography, University of Brasília, Brazil; teacher at the state education network in the Federal District, Brazil. E-mail: juanice.ahss@ yahoo.com.br.

${ }^{4} \mathrm{PhD}$ in Geography, Paulista State University Júlio de Mesquita Filho, State of São Paulo, Brazil, with postdoctoral internship at the University of Porto, Portugal; adjunct professor at the Department of Geography, University of Brasilia, Brazil. E-mail: uabruth@gmail.com.
} 


\section{Introdução}

A Educação Inclusiva retrata as ações da escola que incluem o aluno com necessidades educacionais especiais (NEE) - pessoas com deficiência intelectual, auditiva, visual, física e múltipla, superdotação e altas habilidades ou condutas típicas - tal como especificado na Política Nacional de Educação Especial (BRASIL, 1994) - em todas as suas necessidades, com a obrigatoriedade de cumprir determinações da Constituição de 1988, da Lei de Diretrizes e Bases da Educação Nacional de 1996 e da Resolução do Conselho Nacional de Educação e Câmara de Educação Básica no 2, de 11 de setembro de 2001.

O ensino a esse público deve ocorrer sem discriminações, exclusões e preconceitos, com quebra de paradigmas do modelo educacional tradicional, inovação do enfoque educacional, e ofertar condições aos alunos para prosseguirem seus estudos com qualidade de ensino.

Portanto, para a inclusão acontecer se faz necessário eliminar barreiras quanto ao respeito à capacidade de cada um, em observância ao seu desenvolvimento no ensino comum regular, sem segregações no espaço escolar. Nesse sentido, Mantoan (2006, p. 24) cita alguns impedimentos que interferem negativamente na inovação educacional e na reconstrução da escola brasileira para a inclusão:

A resistência das instituições especializadas a mudanças de qualquer tipo; a neutralização do desafio à inclusão, por meio de políticas públicas que impedem que as escolas se mobilizem para rever suas práticas homogeneizadoras, meritocráticas, condutistas, subordinadoras e, em consequência, excludentes; o preconceito, o paternalismo em relação aos grupos socialmente fragilizados, como o das pessoas com deficiência.

A inclusão na escola se refere à acessibilidade ao espaço físico, ao direito à matrícula no ensino regular, além das práticas e métodos de ensino diferenciados para atender aos estudantes com necessidades educacionais especiais. Mas, para isso, são necessárias mudanças no ensino que garantam a inclusão com eficácia, que reconheçam e valorizem as diferenças e que eliminem as barreiras de acessibilidade e permanência na escola.

Tais ações concentram-se na resolução de problemas de forma cooperativa, com as estratégias de ensino voltadas para o professor e o aluno, diferentemente do modelo tradicional que tinha como base um programa dirigido ao aluno segregado. Esse espaço, sempre que necessário, deve ser adaptado a fim de suprir as necessidades educacionais específicas dos estudantes. 
É necessário o cumprimento da Lei n ${ }^{\circ}$ 13.146/2015, conhecida como Lei Brasileira de Inclusão (LBI), que atribui a obrigatoriedade, ao sistema de ensino, de se adequar para dar o suporte necessário a esses alunos, tanto na infraestrutura da instituição como na formação dos profissionais de ensino para acolher e melhorar a qualidade do ensino junto à diversidade, tanto no aspecto da estrutura física, como no ensino, dentre outras exigências.

Nesse sentido, tanto o sistema de ensino quanto o docente devem cuidar para que o processo avaliativo desse público não seja discriminatório, e ao aluno com deficiência intelectual seja oportunizado aprender, e que ele seja valorizado independentemente das diferenças individuais.

O estudante com deficiência intelectual e os demais que apresentam diferentes necessidades educacionais especiais têm o direito de receber acompanhamento por professores especializados do ensino especial no atendimento educacional especializado de ensino nos contraturnos da matrícula. Esse atendimento é assegurado pelo artigo 208 da Constituição Federal de 1988 que dispõe: “O dever do Estado com a educação será efetivado mediante a garantia de [...] III - atendimento educacional especializado aos portadores de deficiência, preferencialmente na rede regular de ensino" (BRASIL, 1988). E isso se faz com o cumprimento do direito a uma educação apropriada no ambiente escolar sem restrição e sem estigmas.

O sistema de ensino, ao cumprir a lei, inclui de forma diligente todas as pessoas integrando-as independentemente de cor, classe social, condições cognitivas e físicas. Segundo Stainback e Stainback (1999, p. 21): “em um sentido mais amplo, o ensino inclusivo é a prática da inclusão de todos independentemente de seu talento, deficiência, origem socioeconômica ou origem cultural - em escolas e salas provedoras onde todas as necessidades dos alunos são satisfeitas".

A inclusão afasta o aluno com deficiência intelectual do estigma social, da marginalização, de medir o quanto ele aprendeu do conteúdo ou do quanto o professor foi capaz de ensiná-lo, e lhe garante o cumprimento do direito a estudar em escolas regulares, compartilhando as mesmas experiências e aprendizados com os estudantes que apresentam ou não NEE em sala de aula. 


\section{O ensino de Geografia junto a alunos com deficiência intelectual}

A compreensão do processo de aprendizagem dos alunos com deficiência intelectual requer o rompimento com os paradigmas tradicionais de nivelamento de inteligência e a criação de outras formas de ensiná-las. Anache (2011, p. 110) afirma que:

A aprendizagem é compreendida como um processo interativo em que convergem, em toda a sua riqueza, as diferentes formas de subjetividade social. Nela se agregam configurações subjetivas (grupais e individuais) que se articulam nos distintos níveis da vida social, agindo de maneira diferenciada nas diversas instituições e grupos. Os seres humanos, por meio das mediações estabelecidas no curso de sua vida, desenvolvem alternativas de ação que podem resultar no desenvolvimento da sua personalidade.

Para Japiassú e Marcondes (2006, p. 183), a subjetividade é: “característica do sujeito; aquilo que é pessoal, individual, que pertence ao sujeito e apenas a ele [...]. Interioridade”. E isso vai ao encontro do pensamento de Vygotsky (1997), para quem a subjetividade se caracteriza pela constituição de sistemas simbólicos e de sentido subjetivo, integra os aspectos constitutivos da personalidade, como as vivências das situações que os sujeitos enfrentam e a consequente organização do seu mundo. Desse modo, as pessoas aprendem, portanto, com o sistema simbólico, e não somente com o intelecto.

Portanto, é importante considerar que a aprendizagem é inteiramente pessoal, se dá de maneira individualizada, em um processo contínuo de o aluno compreender, interpretar e processar a comunicação, além de sintetizar significados, a partir do contato e interação com pessoas e fatos nos mais diversos ambientes de aprendizagem.

Conhecer e compreender o aluno com deficiência intelectual faz-se necessário para incrementar metodologias e estratégias promovedoras do desenvolvimento da aprendizagem, e para isso devem-se considerar os recursos relacionais (o compartilhamento de conhecimento através dos relacionamentos colaborativos entre o corpo docente e a comunidade escolar) empregados no processo de ensino. Procedimento que move o aluno em direção ao conhecimento, possibilitando a ele explorar o pensamento do outro e poder interferir nele, construindo e reconstruindo o conhecimento por meio das interações.

Os alunos com deficiência intelectual, mediante sua capacidade cognitiva, são capazes de se apropriar e de mobilizar o conhecimento geográfico para realizarem reflexões de teor crítico no seu espaço de vivência, bem como de atuar nessas práticas espaciais em prol da transformação social. Concordamos com Anache (2011, p. 132): o professor, ao proporcionar 
aos alunos situações de aprendizagem mais próximas dos interesses deles, oferece-lhes possibilidades de transformar o que lhes foi apresentado a partir de suas referências, podendo expressar suas criações em diferentes graus e em diferentes contextos.

As atividades cognitivas das pessoas com deficiência foram analisadas por Russo (1994 apud ANACHE, 2001, p. 11) sob “dois ângulos: os aspectos primários, que se referem ao nível de comprometimento neurológico da pessoa, detectado por uma avaliação médica e que, no decorrer da sua história, possa levá-la a uma delimitação secundária (segundo ângulo)", caracterizada pela ausência de experiências socioculturais normalmente vividas. Anache (2011, p. 112) assim interpreta a análise de Vygotsky:

Reconhecer os núcleos primários e os secundários para fins educacionais significou estudá-los em conexão com os mecanismos compensatórios construídos pelo aluno. Esse reconhecimento não implica criar espaços homogêneos de ensino, mas sim, construir processos de ensino com objetivos, recursos e estratégias diversificadas para que seja possível atender às necessidades educacionais especiais dos estudantes com deficiência intelectual.

Para que um aluno com deficiência intelectual possa compreender o conteúdo de Geografia, é imprescindível o empenho docente para além do currículo; o trabalho colaborativo e flexível: a interação docente com o atendimento educacional especializado da escola em busca de colaboração com as adaptações e dinâmicas de ensino, sobretudo porque os alunos podem aprender e acompanhar os conteúdos do currículo do ensino regular, porém o tempo necessário e o aprendizado são individualizados e precisam ser reconhecidos e ampliados. De acordo com Fernandes (2007, p. 40):

Quando pensamos em uma nova escola e uma nova sociedade, orientadas por valores democráticos como o respeito às diferenças, aos direitos humanos, à dignidade da pessoa humana, mais se tem consciência do papel do professor/educador, cujo desempenho extrapola, em muito, o de transmissor de conhecimentos prontos e acabados.

Cada um possui condições de aprendizagem diferenciadas e, por esse motivo, é preciso levar em consideração as desigualdades de capacidade cognitiva, interesses e experiências. Nessa perspectiva, para o desenvolvimento da aprendizagem do estudante com deficiência intelectual, é essencial que o acompanhamento pedagógico seja seguido com cautela e respeito a cada avanço cognitivo, na escrita, na leitura, na contextualização das experiências vividas e nas práticas propostas dentro do espaço escolar. 
Sendo assim, o progresso cognitivo requer a execução de feedback do tema elucidado, propiciando ao aluno melhores condições de compreensão do currículo escolar, visando atender às necessidades do estudante com deficiência intelectual. As práticas pedagógicas precisam ser planejadas em consideração à diversidade de fatores que definem a deficiência intelectual individual de cada aluno, podendo haver muita diferença entre eles.

Portanto, deve-se priorizar quesitos especiais na elaboração do currículo de Geografia, tendo em vista a carência do aluno, para assim realizar a flexibilização e adequação curricular. Nessa concepção, o ensinar e o aprender Geografia se constituem em compreender o espaço geográfico como elemento e meio de transformações sociais, políticas e tecnológicas que nortearam tais modificações.

As práticas de ensino de Geografia efetivam-se ao considerar os interesses das classes populares, o saber e a realidade do estudante como sujeito para o estudo do espaço geográfico, tomando o cuidado de priorizar os aspectos visíveis e observáveis. No entanto, é preciso proporcionar ao estudante a compreensão do todo. Para Azevedo, Steinke e Leite (2014), ao processo de ensinar e aprender Geografia corresponde diferenciar a aplicação do conhecimento geográfico:

A Geografia Escolar pressupõe uma aplicabilidade dos conhecimentos ditos geográficos e é pautado (sic) pelo currículo, pelo fazer pedagógico do professor, num determinado contexto de tempo e espaço; é, também, orientado (sic) a fornecer ao aluno uma possibilidade de leitura de mundo, uma compreensão da realidade, a partir de elementos que lhe sejam significativos ou apresentem a possibilidade de significação (AZEVEDO; STEINKE; LEITE, 2014, p. 159).

Conforme Castellar (2005, p. 213), para que a Geografia tenha sua importância reconhecida no âmbito escolar, superando antigos rótulos, é preciso que sejam realizadas "mudanças na postura do corpo docente em relação ao como, para quê e para quem ensinar Geografia escolar”. Dessa forma, é imprescindível ressignificar o saber-fazer nas aulas de Geografia, considerar e articular os saberes geográficos e pedagógicos quanto ao contexto empírico do aluno, suas nuances e especificidades de aprendizagens.

Todavia, Castellar (2005) salienta que o docente deve inovar as metodologias de ensino, melhorar a organização dos conteúdos, deixar claros os objetivos de ensino, as etapas realizadas, numa linguagem própria da Geografia em uma perspectiva de mobilização dos conhecimentos pedagógicos (didática/metodologias de ensino) e o pensar geográfico (epistemologia/ciência). 
Ao tratar do ensino de Geografia - tanto aos alunos com deficiência intelectual como aos demais alunos, sem deficiência - devem ser ensinados os conteúdos, conceitos e temas geográficos, dando ênfase a como esses saberes geográficos contribuem para o entendimento do mundo, com o intuito de dar embasamento a esses alunos para agir no mundo, respeitando as suas limitações à autonomia. E para tal alcance, deve-se focar, nos saberes geográficos, na relação das experiências vividas do estudante, pois a correlação dos conhecimentos os auxilia na realização da leitura de suas práticas espaciais e pode contribuir a favor do desenvolvimento individual de valores e de atitudes no espaço vivido, nas relações entre sociedade e meio, percebendo-se e tomando decisões conscientes em virtude do contexto.

Sabe-se que o aprendizado humano não se efetiva por apenas um único método, ocorre por múltiplos caminhos bem amplos em variadas tentativas, nas quais acontecem acertos e erros. Porém, nesse processo, torna-se necessário dispor de vários recursos lúdicos como elementos de mediação pedagógica que melhorem não apenas os processos de significação, mas as aprendizagens múltiplas e sua aplicabilidade cotidiana. Não há um procedimento padrão de estratégia adequada de ensino para a aprendizagem. No entanto, Mantoan (2003, p. 34) faz a seguinte análise:

Tem-se um ensino de qualidade a partir de condições de trabalho pedagógico que implicam formação de redes de saberes e de relações, que se entrelaçam por caminhos imprevisíveis para chegar ao conhecimento; existe ensino de qualidade quando as ações educativas se pautam na solidariedade, na colaboração, no compartilhamento do processo educativo com todos os que estão direta ou indiretamente nele envolvidos, que, no mínimo, atende às necessidades, interesses e capacidades de todos, sem discriminações, categorizações ou exclusões.

Não existe um método único que viabilize e acerte o aprendizado dos sujeitos em questão, somente o acesso ao sistema de ensino não dá conta das necessidades do aluno com deficiência intelectual na escola regular, é preciso que haja o devido cuidado pedagógico em suas investiduras de possíveis aprendizagens.

Nesse sentido, o ensino de Geografia voltado ao público da Educação Inclusiva, e em particular aos alunos com deficiência intelectual, exige maior atenção, criatividade e dedicação por parte dos professores que estão em contato direto com eles para, assim, consolidar um caminho de construções e reconstruções pedagógicas mais atrativas para todos.

Pessoas com deficiência intelectual, em sua individualidade, apresentam no âmbito da aprendizagem, dificuldades no processo mental e no raciocínio, um obstáculo à apropriação do conhecimento das disciplinas escolares. Mas isso não significa que elas sejam incapazes de 
aprender e compreender os conteúdos curriculares geográficos e os demais conteúdos das disciplinas pertinentes à escolarização.

Dentre as diversas práticas que envolvem o desenvolvimento humano, o uso de métodos diferenciados de ensino adequados à singularidade dos casos específicos de deficiência intelectual possibilita diminuir as dificuldades apresentadas e melhorar a aprendizagem dos alunos.

\section{Práticas geográficas na horta escolar}

Os conteúdos de Geografia desenvolvidos nas séries finais do ensino fundamental com ação direta em prática são mais bem compreendidos pelos alunos. Poder-se-ão implementar ações pedagógicas de transformação da realidade e de desenvolvimento do saber geográfico considerando suas diversas implicações para o contexto escolar e local, sobretudo, redefinir práticas, currículos, conteúdos, conceitos e métodos de ensino. Gadotti (2000, p. 42) salienta a importância de os conteúdos programáticos terem relação com a vida:

Os conteúdos das disciplinas do saber escolar atual refletem ainda o currículo clássico. A vida cotidiana, a violência, a sensibilidade, a subjetividade, não são levadas em conta. Há muito de arbitrário e cultural na escolha de conteúdos programáticos. Nos últimos anos, as novas propostas curriculares começam a dar cada vez mais importância aos chamados "temas transversais" - ética, saúde, meio ambiente, diversidade cultural, gênero, consumo etc. - realçando os vínculos entre educação e vida. A educação deve ser tão ampla quanto a vida.

Nesse sentido, os conteúdos devem ser adaptados à realidade da aprendizagem dos alunos com deficiência intelectual, com ênfase aos significados da vida. Esses conteúdos são norteados pelos Parâmetros Curriculares Nacionais (PCN) para o ensino fundamental anos finais (BRASIL, 1998) e pela Secretaria de Estado de Educação do Distrito Federal. (DISTRITO FEDERAL, 2014)

Portanto, a utilização da horta escolar como recurso e estratégia de ensino e aprendizagem dos conteúdos curriculares de Geografia aos alunos com deficiência intelectual traz contribuições, tanto aos alunos com ou sem deficiências, quanto aos professores e à comunidade escolar.

$\mathrm{Na}$ expectativa de ensinar para todos, buscou-se desenvolver o ensino de Geografia por meio da horta. Por meio do auxílio desse recurso aumentam as possibilidades de construção de novos conhecimentos, por ser uma forma de os estudantes aprenderem a fazer 
fazendo, ou seja, um meio interdisciplinar de construir o seu próprio conhecimento realizado por meio da prática e dos saberes vivenciados.

A horta escolar foi o espaço das observações da pesquisa, no qual se desenvolveu o ensino dos conteúdos geográficos por meio de atividades práticas associadas à educação ambiental e às técnicas de manejo de cultivos de hortaliças. Desde o planejamento até a sistematização dos conteúdos geográficos de maior relevância do $6^{\circ}$ e do $9^{\circ}$ anos do ensino fundamental séries finais, ao desenvolvimento das atividades práticas até a colheita e formação do canteiro de plantas medicinais com espécies do Cerrado, as atividades foram adaptadas aos estudantes com deficiência intelectual.

Os conteúdos geográficos estudados foram: preservação ambiental; solos e suas propriedades físicas - textura, densidade, estrutura, porosidade, permeabilidade, luminosidade, qualidade e quantidade da água, temperatura; fertilidade; matéria orgânica; bioma cerrado; plantas medicinais da região; cadeia ecológica e sustentabilidade ambiental.

A prática na horta oportuniza aprendizagem dinâmica dos conceitos geográficos e possibilita ao professor levantar questionamentos aos problemas locais que envolvem o fenômeno com o lugar. Nesse contexto, a horta escolar potencializa o rendimento escolar e promove ao estudante a apropriação do espaço. Concordamos com Morgado (2006, p. 45) quando ele diz que:

A horta em um ambiente escolar possibilita a ampliação de diversas formas pedagógicas em Educação Ambiental, unindo teoria e prática de uma maneira contextualizada, estreitando relações, auxiliando no processo de ensino/aprendizagem através do trabalho coletivo entre os agentes envolvidos.

A horta escolar, segundo Fernandes $(2007$, p. 12) é identificada em três tipos:

- Hortas Pedagógicas: tendo como principal finalidade a realização de um programa educativo preestabelecido, a Horta Escolar, como eixo organizador, permite estudar e integrar sistematicamente ciclos, processos e dinâmicas de fenômenos naturais. Superando a área das ciências naturais, o(s) professor(es) pode $(\mathrm{m})$ abordar problemas relacionados com outras áreas do conhecimento de forma interdisciplinar, como: matemática, história, geografia, ciências da linguagem, entre outras.

- Hortas de Produção: visam complementar a alimentação escolar através da produção de hortaliças e algumas frutas.

- Hortas Mistas: possibilitam desenvolver tanto um plano pedagógico quanto melhorar a nutrição dos escolares mediante a oferta de alimentos frescos e sadios. 
Nessa perspectiva, as hortas escolares podem atingir vários objetivos, de acordo com Fernandes (2007, p. 12):

- Melhorar a educação dos escolares, mediante uma aprendizagem ativa e integrada a um plano de estudos de conhecimentos teóricos e práticos sobre diversos conteúdos;

- Produzir verduras e legumes frescos e sadios a baixo custo [...];

- Proporcionar aos escolares experiências de práticas ecológicas [...];

- Melhorar a nutrição dos escolares [...].

Logo, todos os aspectos educacionais abordados com a horta escolar também são importantes para que o educando aprenda a consumir as hortaliças produzidas por ele e reconheça que a horta é fonte de enriquecimento alimentar, e assim favorecer a criação de novos hábitos alimentares, além de despertar o seu interesse pelo cuidado com a natureza, o uso sustentável e consolidar os conteúdos geográficos.

A pesquisa de campo na horta escolar teve como objetivos comprovar as informações resultantes dos levantamentos teóricos, bem como acrescentar novas informações, visando contribuir com o trabalho docente no processo de ensino e aprendizagem junto ao estudante com deficiência intelectual; avaliar a eficácia dessa prática em fixar os conhecimentos geográficos para o aluno com deficiência intelectual; fomentar o posicionamento crítico na busca de sugestões de mudanças para a solução de problemas recorrentes ao processo de ensino e aprendizagem junto a esse público-alvo.

Este estudo utilizou a abordagem qualitativa, como recurso metodológico, com efetiva participação, compreensão e interpretação da pesquisadora. Realizou-se por meio de registro em diário de campo; entrevistas semiestruturadas direcionadas aos alunos com DI e aos professores de Geografia; análise de material bibliográfico e documental de registros escolares dos estudantes com DI envolvidos; e construção de material pedagógico interdisciplinar para auxiliar no ensino de Geografia no ensino fundamental anos finais.

Para desenvolver a pesquisa na unidade de ensino pública do DF, obtivemos autorização da Subsecretaria de Formação Continuada dos Profissionais da Educação (EAPE/SEEDF), da Coordenação Regional de Ensino, do gestor da unidade de ensino e dos pais/responsáveis dos seis alunos sujeitos, os quais assinaram o Termo de Consentimento da Participação da Pessoa como Sujeito da Pesquisa, assim como os nove professores participantes assinaram o Termo de Consentimento Livre e Esclarecido.

Pretendeu-se, com essa estratégia, desenvolver práticas pedagógicas com os sujeitos da pesquisa a fim de aprimorar a metodologia de ensino e aprendizagem a esse público-alvo e 
apresentar aos professores de Geografia e das diferentes áreas do conhecimento uma nova postura de ensino capaz de ser desenvolvida de forma interdisciplinar.

$\mathrm{Na}$ primeira etapa, a horta foi revitalizada pelos estudantes sujeitos e professores colaboradores, conforme pode ser visto na figura 1. Foi realizada a limpeza, o preparo dos canteiros para os plantios das hortaliças e um canteiro para o plantio das plantas medicinais com espécies do Cerrado.

Figura 1 - Preparo do solo para o plantio

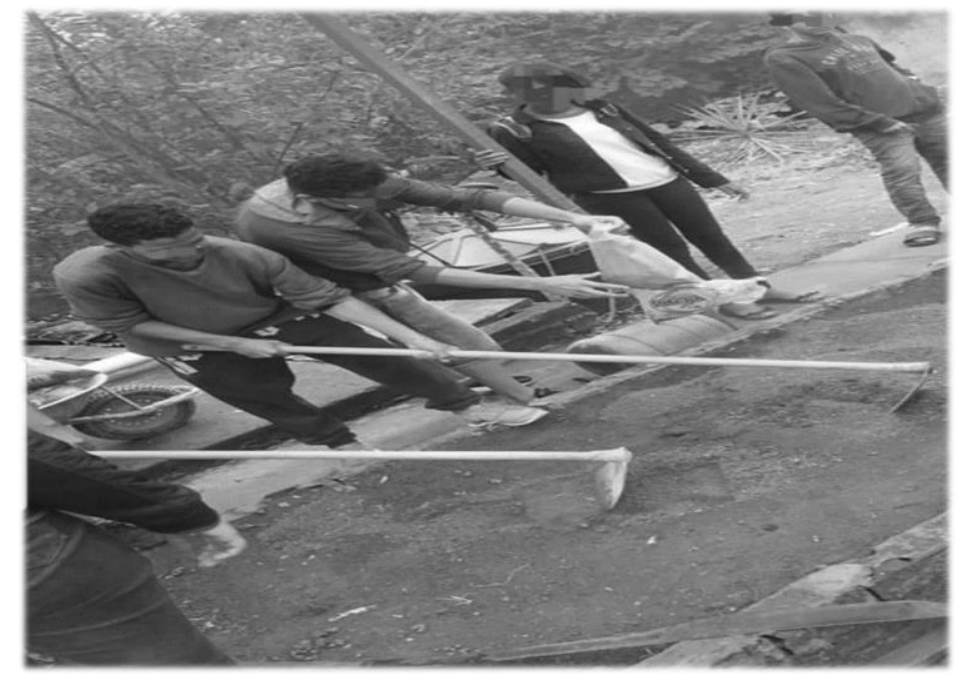

Fonte: As autoras (2019).

Para a revitalização e limpeza da área da horta escolar, correlacionaram-se os conteúdos com outras disciplinas (Ciências, Matemática, Português e Artes). O conteúdo "solos e suas propriedades" foi introduzido em paralelo ao ensino sobre manejo e técnicas de plantio nas aulas práticas, para medir os canteiros, nivelar o solo, calcular a quantidade e tipo de adubo correto para os plantios das hortaliças, no período de abril a junho de 2018.

Nessa fase. foram discutidos vários temas ligados à disciplina Geografia (drenagem, tipos de solos, cadeia ecológica, sustentabilidade e principalmente temas do bioma Cerrado e a riqueza da flora). Buscou-se também trabalhar com a transversalidade e a interdisciplinaridade.

$\mathrm{Na}$ segunda etapa, os alunos sujeitos passaram por aulas teóricas dos conteúdos geográficos preservação e sustentabilidade ambiental, juntamente à turma. As aulas práticas foram realizadas no período de estiagem, a partir de sondagem e discussão dos conhecimentos empíricos sobre preservação e sustentabilidade ambiental a fim de formar uma consciência crítica e cidadã. 
Para o acompanhamento dos cultivos das hortaliças e a realização da manutenção nos canteiros, foram desenvolvidos os conteúdos caracterização e importância da cadeia ecológica, bioma Cerrado e interferência climática sobre as plantas, no período de maio a novembro. Nesse período, foram realizados três ciclos de plantios com alternância de plantações nos canteiros.

A figura 2 mostra o momento da colheita das hortaliças pelos sujeitos da pesquisa, após a maturação do plantio. Em todas as fases foram aplicados os conceitos geográficos e as técnicas de plantio em conexão com os temas ambientais.

Figura 2 - Colheita das hortaliças

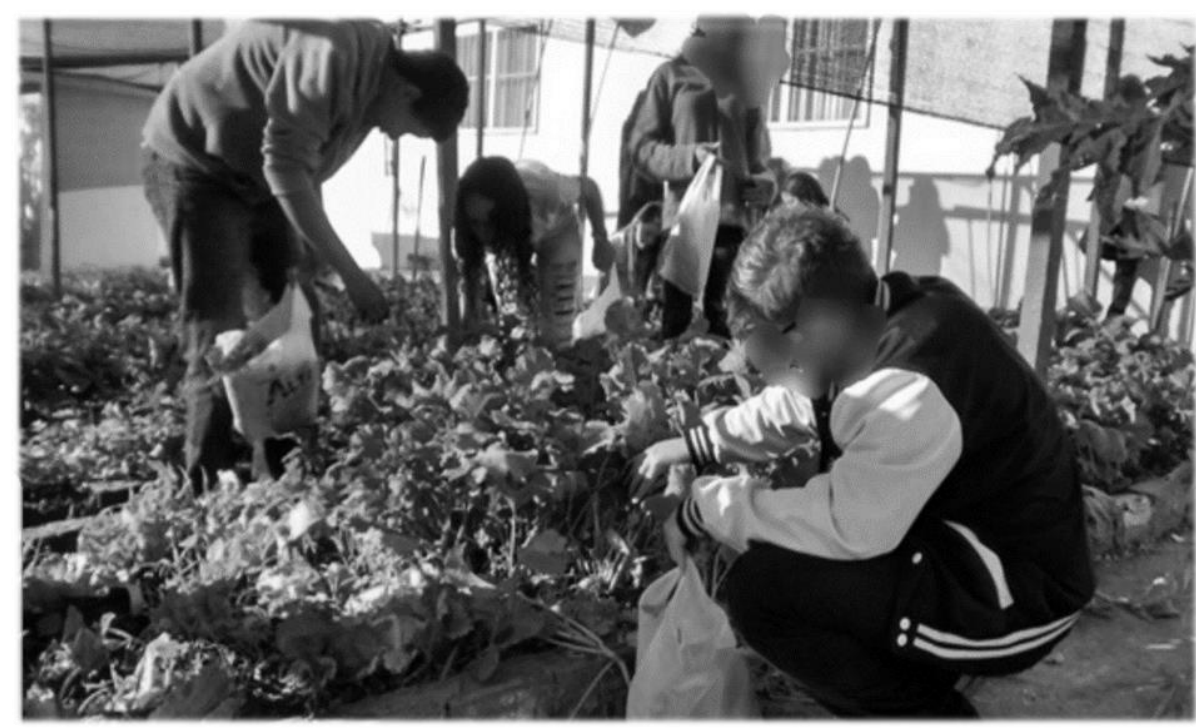

Fonte: As autoras (2019).

$\mathrm{Na}$ última etapa, de cunho pedagógico, os alunos com deficiência intelectual foram estimulados a difundir os conhecimentos geográficos, técnicos e ambientais sobre cultivo de hortaliças e plantas medicinais nas suas casas, por meio da confecção de um roteiro de cultivo realizado na horta escolar, contendo os conteúdos geográficos aplicados, orientações sobre as técnicas de cultivo, sugestões de trabalho interdisciplinar e tarefas que estimulam a fixação dos conhecimentos desenvolvidos na horta.

A pesquisa, iniciada em abril de 2018, procedeu em etapas, com explicações teóricas e aplicação dos conceitos geográficos em todas as fases do cultivo, desde a escolha das hortaliças a serem utilizadas até a colheita e manutenção da horta, seguida do plantio de mudas de plantas medicinais com espécies do Cerrado. Todo o processo finalizou em setembro de 2019. 
A figura 3 apresenta os alunos sujeitos realizando tarefas com o tema horta, introduzido no conteúdo de Matemática. Essa tarefa é uma sugestão de interdisciplinaridade dos temas geográficos com essa área. A tarefa foi elaborada pelas autoras.

Figura 3 - Tarefa de matemática e meio ambiente: planta medicinal carqueja

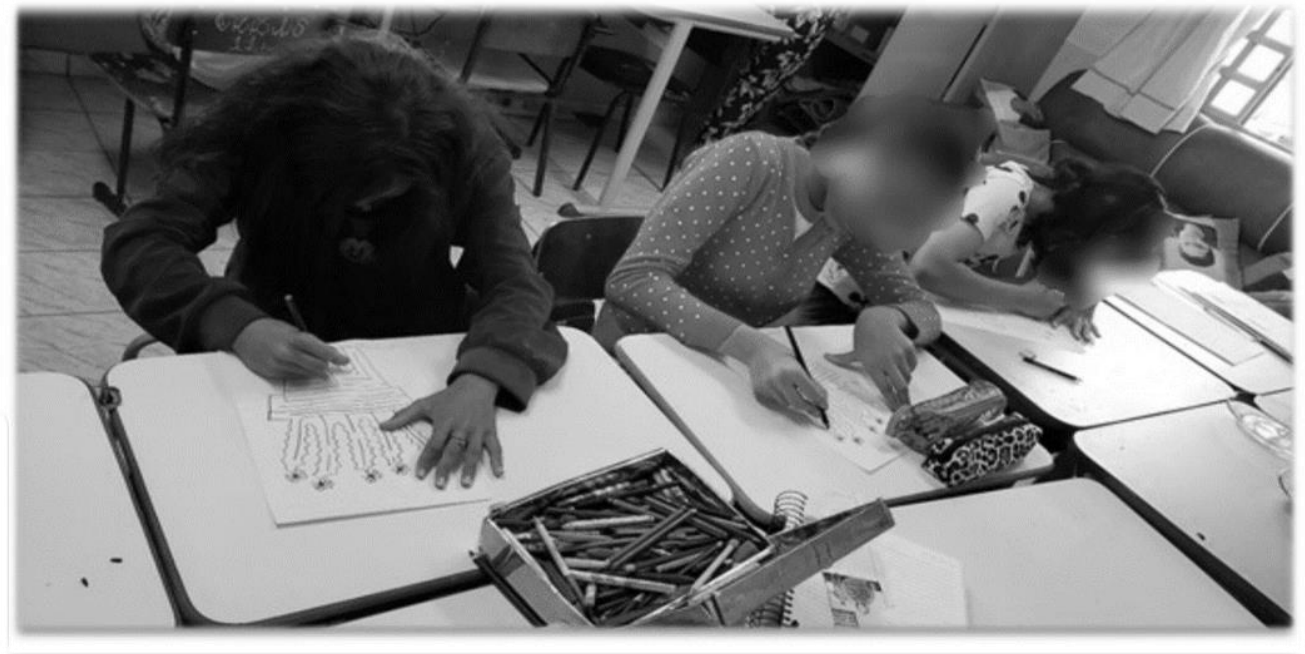

Fonte: As autoras (2019).

Utilizamos, em todas as etapas das atividades práticas, desde a revitalização, o preparo, a condução da horta, a manutenção, até a introdução do canteiro das plantas medicinais e espécies do Cerrado, os seguintes materiais: enxada; enxadeco; ciscador; sancho; pá de transplante; carro de mão; mangueira; regadores; reservatório para água; terra adubada; adubo de galinha; adubo mineral NPK; cal; sementes; mudas e sementes de hortaliças; plantas medicinais; bandejas de isopor e restos de folhagens das árvores podadas existentes no interior da área da escola (corredores e pomar) para cobertura do solo.

O estudo comprovou as informações resultantes dos levantamentos teóricos e acrescentou novas informações identificadas nas observações diretas e nas entrevistas semiestruturadas; também mostrou a realidade no processo de desenvolvimento das aprendizagens dos sujeitos em relação aos conhecimentos geográficos e práticas ambientais.

Dessa forma, analisamos que houve aprendizagem, como pode ser visto no relato do sujeito A: "Eu não sabia que para fazer um canteiro eu tinha que saber que a terra tem propriedades e a gente precisa saber o tanto de água para regar". Nesse relato o aluno fala sobre as propriedades físicas do solo e sua importância na prática.

Já o relato do sujeito B: "Nós moramos em apartamento desde que eu era pequeno e nunca fui em uma horta, e não sabia que precisava medir canteiro e saber a distância de cada 
muda e a profundidade das covas para poder plantar, não vou esquecer". Esse relato complementa o aprendizado em outra área do conhecimento (Matemática).

Também identificamos, em outros relatos, a ocorrência de aprendizagem nessa prática diferenciada, conforme o relato do sujeito D: "Professora, só assim descobri que o manjericão é do Cerrado".

Percebeu-se, em alguns momentos das observações, que nem todos os alunos sujeitos com DI tiveram suas expectativas alcançadas enquanto foram ensinados os conceitos geográficos, no entanto os conceitos geográficos foram ensinados em conexão com a vida cotidiana do aluno a fim de atraí-lo a pensar geograficamente.

Para Cavalcanti (2005) é relevante ter em mente que o ensino de Geografia se constitui em uma série de conceitos, categorias e teorias a partir dos quais constrói seu discurso. Para que o estudante aprenda Geografia, não no sentido de assimilar informações geográficas, é necessário formar um pensamento que lhe permita analisar a realidade à sua volta dentro da perspectiva geográfica. E para isso, é preciso que o docente trabalhe com a linguagem geográfica, uma vez que a importância do aprendizado geográfico consiste em desenvolver a noção espacial e social do ambiente em que vive e do mundo à sua volta.

O empenho do docente em tornar o ensino de Geografia relevante, no entanto, não é nada fácil. O professor precisa ter sensibilidade para trabalhar com os diferentes conceitos da Geografia fazendo uso de recursos pedagógicos diferenciados, como a horta, possibilitando aos sujeitos condições para formularem os próprios conceitos. Logo, o uso da horta como recurso pedagógico requer afinidade com o campo, e só uma minoria possui essa conexão, porém esse fator deve ser respeitado.

Além das contribuições pedagógicas, a horta na escola auxiliou a promoção de hábitos e comportamentos alimentares saudáveis, estimulou os alunos a exercitarem a preservação ambiental, permitiu também o resgate da cultura alimentar brasileira, ao propor tarefas com abordagem aos alimentos de diferentes regiões do Brasil, bem como suscitou diversas habilidades humanas.

Avaliando a eficácia das atividades práticas e da metodologia proposta, pôde ser observado que, à medida que participavam das aulas práticas na horta, os alunos apresentavam um avanço significativo na compreensão dos conteúdos geográficos, caracterizando, assim, a horta como um espaço favorável ao processo de ensino e aprendizagem. 
Pretendeu-se, com essas estratégias, difundir o projeto e os resultados junto aos professores de Geografia e das diferentes áreas do conhecimento, apresentando uma postura de ensino capaz de direcionar o aprendizado do aluno com deficiência intelectual.

Por meio dos resultados apresentados, espera-se que o alcance dos objetivos da pesquisa contribua para: melhorar a aprendizagem e o desenvolvimento do pensamento geográfico espacial e social dos alunos sujeitos com deficiência intelectual; potencializar o rendimento escolar dos alunos sujeitos com DI a partir das práticas na horta; e, principalmente, consolidar a horta escolar como recurso pedagógico, para servir de metodologia de ensino e parâmetros para outras escolas regulares inclusivas; integrar a comunidade escolar, voluntários e demais interessados a participar do cotidiano da escola na rede de ensino público do DF.

A opção por analisar o ensino de Geografia por meio das experiências nas atividades práticas com os alunos com deficiência intelectual deu-se por entender que ações de campo na horta escolar podem contribuir para a internalização dos conhecimentos geográficos e efetivar a inclusão desses alunos. Levamos em consideração a conceituação de Beyer (2006) de que a deficiência é um fenômeno que pertence tanto à esfera individual quanto à esfera social, e que demanda o afastamento de barreiras físicas e atitudinais, além de aquisição de acessibilidade e inclusão social.

Acatamos também o texto da Lei Brasileira de Inclusão (LBI, 2015), Lei n 13.146, '

Art. 2. Considera-se pessoa com deficiência aquela que tem impedimento de longo prazo de natureza física, mental, intelectual ou sensorial, o qual, em interação com uma ou mais barreiras, pode obstruir sua participação plena e efetiva na sociedade em igualdade de condições com as demais pessoas.

Logo, as considerações de Beyer (2006) e as considerações da LBI alicerçam a compreensão da singularidade da deficiência intelectual e nortearam as indagações levantadas que tiveram o intuito de aprofundar nossa reflexão a respeito das possibilidades e os desafios do ensino de Geografia para o aluno com deficiência intelectual.

Nesse sentido, os relatos do professor de Geografia foram relevantes, pois destacaram suas dificuldades em desenvolver uma metodologia de ensino para todos, junto aos estudantes com deficiência intelectual. A aplicação das atividades práticas na horta nas aulas de Geografia resultou em maiores possibilidades de ensino e aprendizagem dos conteúdos geográficos do $6^{\circ}$ ano e do $9^{\circ}$ anos no contexto escolar. Comprovou-se que usar a horta como recurso de ensino potencializa o pensamento geográfico do aluno com deficiência intelectual, 
embora esse seja um tema ainda pouco explorado e discutido, e essa constatação não seja conclusiva. A seguir, o relato do professor, que resume a percepção dos demais entrevistados:

Houve a aprendizagem por outros alunos que trouxeram suas experiências para a escola e ali um ensinava o outro. Mostrava, tipo, como fazer um nivelamento, a profundidade das covas. Coisa que eles gostam de fazer, na prática acho que eles preferem a parte prática do que a parte teórica. Gostavam de participar, mas o aluno A destacava-se mais, ele dedicava-se porque ele queria ter mais contato com a terra, queria colocar a mão na massa, fazia perguntas e comentava sobre as minhas explicações dos conceitos. $\mathrm{O}$ aluno $\mathrm{B}$ queria ajudar, mas era um menino de apartamento, não colocava a mão na massa, talvez não queria se sujar, na horta a gente acaba se sujando, suja sapatos, suja as mãos.

Portanto, para constatar a ocorrência da aprendizagem, que é subjetiva, empregou-se grande esforço. Logo, considera-se que o tratamento dos dados e os instrumentos utilizados indicaram possibilidades de ocorrência de desenvolvimento da aprendizagem dos alunos com deficiência intelectual participantes da pesquisa.

No decorrer do projeto, foi perceptível o quanto as atividades práticas na horta escolar no ensino de Geografia para alunos com deficiência intelectual foram eficazes e significativas para a compreensão e reflexão sobre os saberes geográficos trabalhados, vinculados aos conteúdos curriculares em conexão com a realidade cotidiana dos alunos.

Os conceitos geográficos foram relacionados em várias disciplinas do currículo do ensino fundamental séries finais, em todas as etapas dos cultivos ao consumo de hortaliças e uso de plantas medicinais. Por receberem estímulo durante todo o processo da pesquisa, os estudantes demonstraram interesse e aceitação das propostas das atividades práticas na horta escolar, as quais lhes possibilitaram superar o senso comum e chegar ao saber científico.

A fundamentação teórica das questões ambientais foi de grande contribuição para a realização desse trabalho, pois ao dar visibilidade e valor a outras formas de produzir o espaço e a sociedade, proporcionou aplicar a interdisciplinaridade com as áreas de ciências e educação física.

Essa intervenção de prática no ensino de Geografia, além dos ganhos em múltiplas aprendizagens, valoriza o patrimônio sociocultural e a diversidade ambiental estudados na prática, no desenvolvimento da pesquisa. Portanto, integrou e renovou saberes aos sujeitos e participantes da pesquisa, tanto epistemológicos quanto científicos, proporcionando um entendimento da realidade paradoxal vivida pela sociedade. 


\section{Referências}

ANACHE, A. A. Reflexões sobre o diagnóstico psicológico da deficiência mental utilizado em educação especial. In: REUNIÃO ANUAL DA ANPED, 24., 2001, Caxambu. Anais [...]. Caxambu: Anped, 2001. Disponível em: http://24reuniao.anped.org.br/tp1.htm\#gt15. Acesso em: 20 fev. 2020.

ANACHE, A. A. Aprendizagem de pessoas com deficiência intelectual: desafios para o professor. In: MITJÁNS MARTÍNEZ, A.; TACCA, M. C. V. R. (org.). Possibilidades de aprendizagem: ações pedagógicas para alunos com dificuldade e deficiência. Campinas, SP: Alínea, 2011. p. 109-138.

AZEVEDO, R. M.; STEINKE, V. A.; LEITE, C. M. C. A Fotografia como recurso lúdico para o ensino de geografia. In: STEINKE, V. A.; REIS JÚNIOR, D. F.; COSTA, E. B. (org.). Geografia e fotografia: apontamentos teóricos e metodológicos. Brasília: Editora UnB, 2014. p. 159.

BEYER, H. O. Educação inclusiva ou integração escolar?: implicações pedagógicas dos conceitos como rupturas paradigmáticas. In: SEMINÁRIO NACIONAL DE FORMAÇÃO DE GESTORES E EDUCADORES, 3., 2006, Brasília. Ensaios pedagógicos. Brasília: MEC/Secretaria de Educação Especial, 2006. p. 277-280. Tema: Educação inclusiva: direito à diversidade. Disponível em:

http://portal.mec.gov.br/seesp/arquivos/pdf/ensaiospedagogicos2006.pdf. Acesso em: 16 maio 2019.

BRASIL. [Constituição (1988)]. Constituição [da] República Federativa do Brasil. Brasília: Senado Federal, 1988.

BRASIL. Ministério da Educação. Lei de Diretrizes e Bases da Educação Nacional. Lei n ${ }^{\circ}$ 9.394, de 20 de dezembro de 1996. Estabelece as diretrizes e bases da educação nacional. Brasília, DF, 1996.

BRASIL. Ministério da Educação. Lei n ${ }^{\circ}$ 13.146, de 6 de julho de 2015. Institui a Lei Brasileira de Inclusão da Pessoa com Deficiência (Estatuto da Pessoa com Deficiência). Diário Oficial da União. Brasília, 7 jul. 2015.

BRASIL. Ministério da Educação. Conselho Nacional de Educação. Câmara de Educação Básica. Resolução no 2, de 11 de setembro de 2001. Estabelece diretrizes nacionais para educação especial na educação especial na educação básica. Diário Oficial do Distrito Federal. Brasília, DF, 11 set. 2001. Disponível em:

http://portal.mec.gov.br/cne/arquivos/pdf/CEB0201.pdf. Acesso em: 21 dez. 2019

BRASIL. Ministério da Educação. Secretaria de Educação Especial. Política Nacional de Educação Especial. Brasília: MEC/SEESP, 1994.

BRASIL. Ministério da Educação. Secretaria de Educação Fundamental. Parâmetros Curriculares Nacionais: terceiro e quarto ciclos do ensino fundamental. Brasília: MEC/SEF, 1998. 
CASTELLAR, S. M. Educação geográfica: a psicogenética e o conhecimento escolar. Cad. Cedes, Campinas, v. 25, n. 66, p. 209-225, maio-ago. 2005. Doi: 10.1590/S010132622005000200005 .

CAVALCANTI, L. Cotidiano, mediação pedagógica e formação de conceitos: uma contribuição de Vygotsky ao ensino de Geografia. Cad. Cedes, Campinas, v. 25, n. 66, p. 185-207, 2005. Doi: 10.1590/S0101-32622005000200004.

DISTRITO FEDERAL. Secretaria de Estado de Educação do Distrito Federal. Currículo em Movimento da Educação Básica: Educação Especial. Brasília: SEEDF, 2014.

FERNANDES, M. C. A. Orientações para implantação e implementação da horta escolar. Brasília: MEC, 2007. (Caderno 2).

JAPIASSÚ, H.; MARCONDES, D. Dicionário básico de Filosofia. 4. ed. atual. Rio de Janeiro: J. Zahar, 2006.

GADOTTI, M. Pedagogia da terra. 5. ed. São Paulo: Fundação Peirópolis, 2000.

MANTOAN, M. T. E. Inclusão escolar: o que é? por quê? como fazer? São Paulo:

Moderna, 2003.

MANTOAN, M. T. E. Igualdade e diferenças na escola: como andar no fio da navalha. In: MANTOAN, M. T. E.; PRIETO, R. G.A.; ARANTES, V. A. (org.). Inclusão escolar: pontos e contrapontos. São Paulo: Summus Editorial, 2006. p. 104.

MORGADO, F. S. A horta escolar na educação ambiental e alimentar: experiência do projeto Horta Viva nas escolas municipais de Florianópolis. 2006. 50 f. Trabalho de Conclusão de Curso (Bacharel em Engenharia Agrônoma) - Universidade Federal de Santa Catarina, Florianópolis, 2006.

STAINBACK, S; STAINBACK, W. Inclusão: um guia para educadores. Tradução de Magda França Lopes. Porto Alegre: Artes Médicas, 1999.

VYGOTSKY, L. S. Fundamentos de defectologia. Obras Escogidas. Madri: Visor, 1997. v. 5 .

Submetido em 26 de novembro de 2019.

Aprovado em 15 de abril de 2020. 